\title{
A RECEPÇÃo DA FAMÍlIA NA HOSPITALIZAÇÃo DE CRIANÇAS ${ }^{1}$
}

\author{
Maria Aparecida Crepaldi ${ }^{2}$ \\ Patrícia Bittencourt Varella
}

\begin{abstract}
RESUMO: Fundamentando-se em estudos que discutem a participação de familiares na hospitalização de seus filhos, este trabalho pretende estudar como os familiares de crianças hospitalizadas vivenciam o momento da recepção, que profissional da equipe os acompanha durante os procedimentos iniciais, que informações recebem e quem se encarrega de informá-los, logo que a criança é admitida no hospital em razão de uma doença que necessita de cuidados hospitalares. Os participantes foram 40 pais e se utilizou entrevistas semiestruturadas para a coleta de dados. Estes foram analisados segundo métodos de análise de conteúdo. Os resultados mostraram que os pais vivenciam um estado de ansiedade generalizado, não sabem nomear que profissional os acompanhou, além de se lembrarem de informações esporádicas que dizem respeito, exclusivamente, às suas necessidades imediatas.
\end{abstract}

Palavras chave: hospitalização de crianças, mães acompanhantes, famílias no hospital, recepção de pais.

\section{THE RECEPTION OF FAMILY IA THE CHILDREN'S ADMISSION TO GENERAL HOSPITAL}

\begin{abstract}
Based on studies which discuss the participation of family members in their children hopitalization, this work intends to study how the relatives of hospitalized children experience the moment of reception, which professional of the staff accompanies them during the first procedures, the kind of information is received and who gives the information, as soon as the child is admitted to the hospital on the account of a disease which needs hospital care. In order to colect data 40 parents were interviewed by semi-structured interviews. Data is analised in terms of methods of content analisys. Results indicate that the parents experience a state of generalized anxiety, they can't name the professional who accompanied them, apart from remembering sporadic information which is related exclusively to their immediate needs.
\end{abstract}

Key words: children hospitalization, companion mothers, families in hospital, parent reception.

Já na década de 50, Hohle (1957) afirmava que a lógica em trazer os pais para dentro do hospital era auto-evidente, primeiro porque são pessoas que podem favorecer o desenvolvimento da criança, são figuras de apego, são responsáveis pela criança e, como tal, deveriam ter direito a permanecerem ao lado dela em situação tão adversa, como é a condição de estar acometida por uma doença. Assim, segundo a autora, não havia outra razão maior do que a própria evidência para justificar a necessidade da presença deles.

\footnotetext{
${ }^{1}$ Artigo recebido para publicação em 05/00; aceito em 04/01

2 Endereço para correspondência: Maria Aparecida Crepaldi, Departamento de Psicologia - CHF, Universidade Federal de Santa Catarina, Campus Universitário, Cep 88900-000, Florianópolis, SC, Brasil, Email: crepaldi@chf.ufsc.br
}

Paidéia, FFCLRP-USP, Rib. Preto, ago/dez/2000.
Hohle faz parte de um grupo de enfermeiras norte americanas, que nas décadas de 1950 e 1960 , tomaram medidas efetivas para a inclusão de familiares no atendimento de crianças, fundamentadas nos estudos precursores de Bowlby $(1952,1960)$, Spitz (1945) e Spitz \& Wolf (1946), sobre os danos causados em crianças institucionalizadas, pelo afastamento de suas mães. Estavam, portanto, preocupadas, também, com a preservação da saúde mental das crianças.

Alguns destes profissionais, dentre eles: Coffin (1955), Hohle (1957), Fagin (1962), James e Wheeler (1969), dentre outros, rebelaram-se contra argumentos e medidas hospitalares que justificavam o afastamento dos pais, tais como: era preciso mais 
pessoas para atender, interferiam na dieta das crianças, mostravam-se agressivos com a equipe, dificultavam o contato da equipe com a criança, entre outras.

Coffin (1955) descreveu sua experiência de trabalho com horário irrestrito para visitas, mostrando as vantagens da adoção da participação dos pais para as crianças, em uma época em que familiares não eram admitidos nas enfermarias nos Estados Unidos. Para esta autora, a presença da mãe, evita que as crianças chorem muito, além de parecerem mais felizes. As mães, por outro lado, podem aprender cuidados básicos.

Com a presença dos pais os profissionais ficam mais livres para fazer um trabalho de boa qualidade já que as mães ajudam a fornecer cuidados. Há também maiores trocas entre o hospital e a comunidade (Fagin, 1962).

Segundo James e Wheeler (1969) a presença dos pais evita o desencadeamento de reações emocionais causadas pela separação criança-famílía; eles se encarregam em fazer a mediação entre equipe e criança, acelerando a alta, uma vez que a convalescência é mais rápida.

Assim, as contribuições dos autores acima citados foram fundamentais para o fomento da discussão em torno desta problemática e para o implemento, posteriormente, nas décadas de 70 e 80 , de programas, nos hospitais, que incluíssem os familiares das crianças doentes e hospitalizadas.

Nas décadas de 70 e 80 tornou-se comum então, também no Brasil, a idéia de se implantar programas de alojamento conjunto nas maternidades e, posteriormente, programas mães-acompanhantes e mães-participantes (Andrade e Silva at all, 1982), a partir da necessidade de se humanizar a instituição hospitalar e de se oferecer à criança uma assistência integral. Esse fato levou os pesquisadores a se preocuparem com as relações entre equipe e família (Crepaldi, 1989; Ranna; 1987; Ranna \& Okay, 1980), tendo em vista que a presença desta última implementou uma nova dinâmica ao contexto hospitalar.

A presença de familiares acaba por forçar a adoção de formas alternativas de funcionamento da instituição, a começar pela inclusão, na equipe de saúde, de profissionais de outras áreas que não a médica, habilitados a atender os aspectos psicossociais da clientela, como: psicólogos, terapêutas ocupacionais, recreacionistas, assistentes sociais. Esta medida, nem sempre fácil de ser posta em prática, pressupõe a adoção de uma filosofia de atendimento que questiona a concepção de doença como um fenômeno circunscrito ao corpo, unicamente, o que nem sempre é bem visto pelo saber médico.

Nos últimos anos, porém, constata-se que há uma preocupação em conhecer como a família vê sua inserção no espaço institucional, o que julga ser um bom atendimento, que representações tem sobre 0 binômio saúde-doença e como gostaria de participar do atendimento (Brunnquel \& Koren, 1991; Cameron at al., 1992; Crepaldi, 1999; Diehl at al., 1991; Knafl at al., 1992; Miles \& Maths, 1991).

Neste sentido tem nos interessado o momento de admissão da criança e de seus pais na instituição hospitalar, por considerar que este é decisivo para os acompanhantes, pois se trata de uma situação em que devem tomar decisões como: consentir por escrito a internação, os procedimentos a serem realizados, além de se comprometerem a obedecer às normas do hospital. Também devem se comunicar com parentes e com o local de trabalho para informar sobre o que está ocorrendo. Sem contar com o fato de se configurar como uma situação de dificil manejo, que gera um estado de ansiedade generalizado, provocado pela preocupação com o filho, pela internação inesperada, em muitos casos, já que dificilmente o familiar é convidado a acompanhar os procedimentos de admissão, que compreende, desde a consulta médica, passando pela decisão de que a criança deverá ser hospitalizada, culminando no encaminhamento até a enfermaria devida (Crepaldi, 1999).

Assim o trabalho que aqui se apresenta relata resultados de uma pesquisa realizada junto a familiares de crianças hospitalizadas, cujo objetivo foi o de investigar como os pais vivenciaram o momento da recepção num hospital geral, por ocasião da hospitalização de seus filhos.

\section{Método}

O trabalho foi realizado em uma Unidade de Pediatria de um Hospital Universitário, que admitia acompanhantes durante vinte e quatro horas.

No período de realização da pesquisa registrou-se a internação de 186 crianças nesta enfermaria. Desse total, $97(52,14 \%)$ crianças foram acompanhadas por um membro da família. Dentre estes acompanhantes, $40(42,02 \%)$ foram incluídos na 
amostra. É importante salientar que se adotou como critério de inclusão a permanência do familiar por, pelo menos, um período de 12 horas ao lado do filho e que a internação fosse de, no mínimo, uma semana.

\section{Dos acompanhantes}

Dentre o total de 40 acompanhantes entrevistados, $38(95 \%)$ eram mães biológicas, $1(2,5 \%)$ mãe adotiva e $1(2,5 \%)$ o pai da criança. Pode-se concluir, portanto, que a figura familiar que acompanha a criança na vigência da doença é, em sua grande maioria, a mãe.

A idade média dos acompanhantes entrevistados foi de 32,5 anos, concentrando-se em sua maioria na faixa etária de 21 a 25 anos, em $35 \%$ dos casos. $O$ número de filhos variou de 1 a 8 e atingiu uma média de 4 por família. A maior parte das mães $(62,5 \%)$ não trabalhava fora, e $2(5 \%)$ diziam-se desempregadas; $13(32,5 \%)$ não exerciam atividade profissional.

Todas as famílias pertenciam à população pobre e o sustento delas provinha do trabalho do pai, cuja ocupação referia-se a mão de obra não especializada. As mães que ajudavam no sustento com seu trabalho eram, em sua maioria, empregadas domésticas ou diaristas. Quando o número de filhos era grande, as famílias costumavam contar com a ajuda, financeira ou não, dos filhos maiores, que também se ocupavam de funções semelhantes às dos pais, quer seja no trabalho fora de casa ou doméstico.

\section{Das crianças}

O tempo médio de internação das crianças foi de 33,5 dias, variando entre 7 e $60.33(82,5 \%)$ crianças estavam sendo internadas pela primeira vez, enquanto que $7(17,5 \%)$ constituiam casos de reinternação. A maioria $(57,5 \%)$ era do sexo masculino.

Mais da metade das crianças era lactente de 0 a 1 ano de vida (52,5\%). Em idade pré-escolar encontravam-se $32,5 \%$ e em idade escolar, $15 \%$ das crianças. A maioria $(52,51 \%)$ eta procedente de Florianópolis.

Quanto ao diagnóstico, os quadros mais frequientes foram: síndrome diarréica, pneumonia e desidratação, ou seja, em $75 \%$ dos casos as crianças eram acometidas por doenças chamadas de sociais.
Os demais casos $(25 \%)$ variaram entre patologias que incluem câncer, púrpura, hepatopatias, diabetes, e refluxo.

\section{Procedimentos e instrumentos}

Os dados foram coletados através de entrevistas semi estruturadas, realizadas durante a permanência dos acompanhantes no hospital, obedecidos os critérios de inclusão dos pais na amostra e analisados segundo o método desenvolvido por Bardin (1977) e Crepaldi (1989).

A partir do dado bruto, definiu-se como unidade de análise fragmentos do discurso denominados enunciados. Um enunciado pode ser composto por uma palavra, um período ou uma frase, que tenha um tema central. Estas unidades foram categorizadas e tiveram suas frequiências de ocorrência contadas. Desta forma, um só sujeito pode apresentar vários fragmentos que digam respeito a um único tema.

\section{Resultados}

As categorias temáticas que organizaram os relatos verbais dos participantes foram: quem recebeu a mãe na enfermaria, quem informou a mãe, que informação lhe foi dada.

\section{maria}

Quem recebeu o acompanhante na enfer-

Esta categoria reúne as falas das mães sobre a identificação da pessoa que as recebeu na enfermaria assim que foram admitidas, depois de terem passado pela sala de emergência. Estes dados podem ser vistos na tabela I (a seguir) e agrupam as subcategorias: sujeito indeterminado, médico, enfermeira, ninguém e não respondeu.

Tabela I: Tabela de freqüência e porcentagem de ocorrência das respostas da categoria Quem recebeu a mãe na Enfermaria Pediátrica.

\begin{tabular}{l|c|c} 
Quem recebeu & F & $\%$ \\
\hline Sujeito Indeterminado & 19 & 47,5 \\
Médico & 9 & 22,5 \\
Enfermeira (não sabe o nome) & 8 & 20 \\
Ninguém recebeu & 2 & 5 \\
Não respondeu & 2 & 5 \\
\hline Total & $\mathbf{4 0}$ & $\mathbf{1 0 0}$
\end{tabular}


Pode-se constatar pela tabela I, que grande parte das mães $(47,5 \%)$ demonstrou não reconhecer a que segmento da equipe pertencia a pessoa que as recebeu na enfermaria, caindo a resposta na indeterminação. As mães supõem que seja alguém do corpo de enfermagem, como se pode constatar pelas frases:

Veio, veio sim alguém, me trouxe aqui em cima, não consigo lembrar agora ... Foi, agora eu tão sei se foi uma enfermeira, acho que foi.

Veio uma mocinha que tava lá embaixo, não sei bem qual delas.

Em seguida, 22,5\% dos participantes mencionaram o subtema médico e $20 \%$ o corpo de enfermagem (enfermeira).

Veio um doutor (Entrevistador- Veio alguém contigo do hospital lá de baixo até aqui em cima?) nome dela.

Foi a enfermeira aqui em cima. Eu nem seio

2 entrevistadas afirmaram que não houve recepção e outras duas mães não responderam.

\section{Quem informou?}

A tabela apresentada a seguir reúne as respostas dos acompanhantes sobre a pessoa que os informou inicialmente na enfermaria. Destaca-se que faz parte do trabalho da equipe dar informações aos familiares sobre as rotinas e regras do hospital após a recepção.

Tabela II: Tabela de frequiência e porcentagem de ocorrência das respostas da categoria $Q u e m$ informou a mãe na Enfermaria Pediátrica.

\begin{tabular}{l|c|c} 
Informações obtidas na recepção & F & $\mathbf{\%}$ \\
\hline Rotina do hospital & 56 & 55 \\
Pode ficar se quiser & 21 & 20 \\
Necessário ficar & 16 & 16 \\
Não recebeu informação/Não lem- & 7 & 7 \\
bra & 2 & 2 \\
Outros & & \\
\hline Total & $\mathbf{1 0 2}$ & $\mathbf{1 0 0}$
\end{tabular}

Pode-se observar na tabela II que $45 \%$ das mães afirmaram que a enfermeira deu a informação. Geralmente é o corpo de enfermagem que recebe a família e fornece as informações preliminares, apre- sentando aos pais um roteiro de informações impresso, contendo as normas e demais orientações destinadas aos acompanhantes da criança.

Foi de uma enfermeira. Agora eu não me lembro se foi de uma enfermeira ou... Acho que foi de uma enfermeira, que eu no começo tava assim, elas vieram, trouxeram o papel ... foi a enfermeira sim que me trouxe.

Quinze entrevistados (37,5\%) referiram-se a um sujeito indeterminado como fonte de informação.

Subiu, subiu uma moça, não sei o nome dela, eu acho que eu nem me lembro mais dela, não foi a médica também, foi uma moça que tava com um monte de folha na mão, ai ela tava entregando, trazendo (...) trouxe a minha [roteiro de informações].

Mencionaram o médico 5\% dos participantes e por fim, 7,5\% referem não terem sido informados, ou não se lembrarem da pessoa que os informou.

Foi a médica. (Entrevistador- E quando a senhora internou o E., quem falou sobre a possibilidade de a senhora ficar aqui com ele?)

Não. (Entrevistador- E tu recebestes alguma informação aqui em cima, na enfermaria?)

Olha no momento eu não lembro não. Poderia até dizer porque é uma coisa normal, natural, mas não lembro. (Entrevistador: $\mathrm{E}$ de quem tu recebestes estas informações?)

\section{Sobre a informação recebida}

A Tabela III e IV apresentadas a seguir organizam os dados relativos às falas dos acompanhantes sobre as informações recebidas. A primeira delas (Tabela III) refere-se ao fato de as mães terem ou não sido informadas e a Tabela IV, ao conteúdo destas informações.

Paidéia, FFCLRP-USP, Rib. Preto, ago/dez/2000. 
Tabela III: Tabela de frequiência e porcentagem de ocorrência das respostas da categoria Informações obtidas pela mãe na recepção da Enfermaria Pediátrica.

\begin{tabular}{l|c|c} 
Informações na recepção & F & \% \\
\hline Foi informada & 31 & 77,5 \\
Não foi informada/não se lembra & 7 & 17,5 \\
Não respondeu & 2 & 5 \\
\hline Total & $\mathbf{4 0}$ & $\mathbf{1 0 0}$
\end{tabular}

Observa-se que a maioria dos acompanhantes $(77,5 \%)$ disseram que foram informados durante a recepção, relatando pelo menos um tipo de informação recebida, enquanto que $17,5 \%$ afirmaram não terem sido informados ou não se lembravam se isto havia acontecido.

Tabela IV: Tabela de freqüência e porcentagem de ocorrência das respostas da categoria Informações obtidas pela mãe na recepção da Enfermaria Pediátrica.

\begin{tabular}{l|c|c} 
Informações na recepção & F & \% \\
\hline Rotina do hospital & 56 & 55 \\
Pode ficar se quiser & 21 & 20 \\
Necessário ficar & 16 & 16 \\
Não recebeu informação/Não Lembra & 7 & 7 \\
Outros & 2 & 2 \\
\hline Total & $\mathbf{1 0 2}$ & $\mathbf{1 0 0}$
\end{tabular}

Sobre o tipo de informação recebida durante a recepção, a maioria das respostas (55\%) referiu-se à rotina da enfermaria, o que envolve regras, colocadas em um roteiro do hospital, procedimentos e condições de alojamento do hospital.

... ela disse que as refeições, seriam três refeições, ela disse que o banheiro era esse de fora, banheiro pra tomar banho é aquele lá dentro, fumar seria aqui o lado de fora e no banheiro, que eu podia trazer a menina pra tomar sol, tinha parque, tinha tanque pra lavar roupa, que eu não podia usar roupa indecente aqui dentro, mas o que, acho que émais ou menos isso, assim por cima, é mais ou menos isso que eu lembro.

Eles têm um papel dizendo tudo, o que a gente tem que fazer, e eu ganhei da enfermeira.
A possibilidade de acompanhar o filho durante a hospitalização foi mencionada como informação recebida durante a recepção em $20 \%$ das mães:

Eu cheguei aqui elas disseram que se a mãe queria ficar podia ficar, se a mâe não quisesse que elas atendiam bem as crianças.

Em $16 \%$ das respostas as mães teriam sido convencidas a permanecer no hospital porque a equipe disse que isto era necessário. Uma análise mais acurada das respostas mostrou que foram utilizados os seguintes argumentos: que o acompanhamento familiar é importante para a criança $(75 \%-\mathrm{N}=16)$ e que seria bom permanecer no hospital para ajudar no cuidado das crianças ( $25 \%-\mathrm{N}=16$ ), como pode ser visto nos enunciados a seguir:

Falou, o médico falou que era necessário [acompanhar], que a companhia da mãe era importante.

Ela falou que aqui era bom as mäes ficarern, prá ajudar eles, que eram muitas crianças e poucas enfermeiras.

$7 \%$ dos acompanhantes nã̃o se lembravam de ter recebido quaisquer informações durante a recepção.

Olha, no momento eu não me lembro como é que é, eu tava muito nervosa, eu não sei.

Por fim, apenas $2 \%$ respostas foram enquadradas na categoria outros, sendo que uma delas diz respeito aos enunciados não é necessário ficar e é bom para mãe acompanhar.

Não. Com a V [criança hospitalizada], a enfermeira disse que não era preciso ficar.

É, era bom pra criança e pra mim, ela [enfermeira que forneceu a informação] achava.

\section{Discussão e Considerações Finais}

Os resultados desta pesquisa mostram que o hospital procura manter perto um membro da equipe por ocasião da recepção das crianças e dos acompanhantes. Chama atenção, porém, o fato de não haver uma interação da pessoa que recebe com a mãe, no ato da internação, que seja suficientemente acolhedora, e que, portanto, possa-se caracterizar como personalizada. A mãe relata ter tido "alguém" que a recebeu mas não sabe dizer quem é, já que na maioria das vezes ela não identifica a que segmento da equi- 
pe a pessoa pertence ou o seu nome. Isto é válido tanto para o profissional que a recebeu na enfermaria, quanto para aquele que lhe deu as primeiras informações, que pode ou não ser a mesma pessoa.

Embora as mães tenham dito que foram informadas de que poderiam permanecer no hospital, o que chama atenção é que elas ainda estão sendo vistas como ajudantes nos serviços, como cuidar da criança, tendo $16 \%$ delas mencionado isto. (vide tabela IV). Confirmam este fato os resultados de outra pesquisa feita na mesma enfermaria, sobre as atividades que as mães realizavam com a criança durante a internação, sendo que em $70 \%$ dos casos elas desempenhavam tarefas ligadas aos cuidados básicos com os filhos, como, dar banho, trocar fralda, alimentar (Crepaldi, 1998).

Assim na recepção, as mães pesquisadas receberam dois tipos diferentes de informação: primeiro de que seria possível permanecer se ela o desejasse e/ou pudesse, e em contrapartida, que ela precisaria ficar, para inclusive ajudar nos serviços. Esta oposição de informações denota diferenças na concepção do profissional que recebe, sobre o papel do acompanhante, gerando diversidade no que é veiculado.

As famílias devem ajudar se desejarem, mas mas isto não deve ser compulsório, já que cuidar no hospital é tarefa da equipe de saúde, sendo os familiares coadjuvantes. Sem contar que a equipe poderia incluir na sua orientação que presença do acompanhante é um fator que ajuda a promover o bem estar da criança.

Constatou-se, ainda, que as informações obtidas durante a recepção, assimiladas pela mãe, foram aquelas relativas às necessidades mais imediatas.

Tem-se como exemplo mães que vieram de outras cidades para o hospital e enfatizaram, em seus relatos, informações sobre o alojamento que a Instituição oferece, já que esta era uma condição primeira para que pudessem permanecer, como pode ser visto no enunciado a seguir.

Veio uma senhora conversar comigo, que eu tava mais calma, aí ela veio disse que tão podia ser usado nada do hospital que eu podia permanecer que eu teria café, almoço, janta, e que elas não poderiam me dá cama, fornecer cama, porque o hospital não tinha condições, mas uma cadeira, que servia de espreguiçadeira assim, espichava pra trás e dai eu podia permanecer aqui no hospital junto com a minha filha. E dai podia acompanhar ela o tempo 38 todinho até ela ganhar alta, e que eu ganharia café, almoço e janta, daria pra mim tomar banho e se eu fosse de longe eu poderia usar a lavanderia pra lavar minhas roupas. Tudo isso.

Outras mães, ainda, demonstraram ter assimilado mais prontạmente informações sobre regras que as atingiam diretamente, como por exemplo, a forma mais adequada de se vestir na enfermaria, ou a não interferência na dieta da criança, trazendo alimentação de fora. A seguir tem-se um exemplo desta condição.

Que não podia usar saia, blusa decotada, apesar que eu tô usando que a outra minha tá suja, $e$ não pode carregar nada de fora assim, compra pra trazer pra dentro, só alimentação da criança mesmo, se no caso nós quiser fazer um lanche nós podemos fazer ou na salinha ou do lado contrário na escadaria, mais nada. Essas coisa assim. [...] Short também não pode usar.

Uma informação também importante para os pais foi a de que poderiam permanecer com ofilho no hospital, já que ficar longe do mesmo é a grande preocupação dos pais.

Outro fator que deve ser considerado no ato da internação é o estado emocional das mães no contexto da recepção. Quando chegam ao hospital e não esperam que o filho venha a ter que ficar, geralmente entram em ansiedade, por temerem a gravidade da doença, pelo grande número de fatores e complexidade das situações com as quais têm que lidar, pela ausência do lar, por terem que avisar o marido e os parentes, apoiar o filho, além de estarem atentas a tudo o que passa a acontecer no hospital após a admissão, como mostrado em outro trabalho de pesquisa realizado no Instituto da Criança (Crepaldi, 1999). Este conjunto de fatores costuma interferir, também, na assimilação das informações.

Pode-se constatar, através dos resultados, que a equipe não possui uma uniformidade de procedimentos para informar a família sobre o motivo da permanência dos pais. Pode-se hipotetizar que não seja consenso, para esta equipe, a importância do acompanhante para a criança, nem tampouco os objetivos de sua permanência ao lado do filho, sem contar com o des-

Paidéia, FFCLRP-USP, Rib. Preto, ago/dez/2000. 
conhecimento do papel que os familiares podem exercer, uma vez presentes. As informações que os pais assimilaram com maior frequiência, diziam respeito às rotinas, normas e regras do hospital, o que denota ainda que são as que mais preocupam a equipe, no sentido de que os pais não burlem estas normas para não interferir no trabalho que é realizado.

Evidencia-se, em especial a partir destes resultados, a necessidade de que a equipe uniformize a informação que deseja transmitir e, mais do que isso, conscientize-se de que o acompanhamento familiar é importante para favorecer o desenvolvimento da criança hospitalizada. Para tanto deve orientar a família no sentido de manter no hospital alguém de quem a criança goste, que lhe seja familiar, respeitando, na medida do possível, suas preferências e as possibilidades da família, além de seprontificar a orientar os familiares.

Tendo em vista estes fatores, a recepção dos acompanhantes evidencia-se como tão importante quanto a recepção da criança. As informações iniciais devem ser claras, dosadas e sua transmissão deve levar em conta o momento que a família está vivenciando que geralmente é ansiogênico.

\section{Referências Bibliográficas}

Andrade e Silva, P.S.L, Aguiar, A.A., Souza, I.S. \& Almeida, I.N. (1982). Internação conjunta (IC) mãefilho em enfermaria coletiva de hospital conveniado com o INAMPS.Jornal de Pediatria, 52(6):391-394.

Bardin, L. (1977). L'Analise de Contenu. Paris, PUF.

Bowlby, J. (1952).Maternal Care and Mental Health. Geneva: OMS

Bowlby, J. (1960). Separation Anxiety. The International Journal of Psycho-analysis,_41:89-113.

Brunnquel, D. \& Koren, D. P. (1991). Emotions in pediatric emergencies: What we know, what we can do. Children's health care, 20(4):240-247.

Cameron, S. J., Snowdon, A. \& Orr, R.R. (1992). Emotions experienced by mothers of children with development disabilities: Children's health care, 21(2):96-101.

Coffin, M.A. (1955). Visiting hours for parents. American Journal of Nursing, 55(3):329.

Crepaldi, M.A. (1989). Hospitalização Infantil: estu-

Paidéia, FFCLRP.USP, Rib. Preto, ago/dez/2000. do das interações família-equipe hospitalar. Dissertação de Mestrado, PUC-RJ, Rio de Janeiro.

Crepaldi, M.A. (1998). Estudo do programa de inserção da família no atendimento à criança hospitalizada: o relato de familiares sobre a assistência recebida. Relatório Parcial de Pesquisa. UFSC, Florianópolis.

Crepaldi, M.A. (1999). Hospitalização na Infância: representações sociais da família sobre a doença e hospitalização de seus filhos. Taubaté: Cabral Editora Universitária.

Diehl, S.F., Moffitt, K.A. \& Wade, S.M. (1991). Focus group interview with medically complex needs: An intimate look at their perceptions and feelings. Children's health care, 20(3):170-178.

Fagin, C.M. (1962). Why not involve parents when children are hospitalized? American Journal of Nursing, 62(6):78-79.

Hohle, B.M. (1957). We admit parents too. American Journal of Nursing, 57(7):865-867.

James, V.L. \& Wheeler, W.E. (1969). The care - byparent unity. Pediatric , 43:488-498.

Miles, M.S. \& Mathes, M. (1991). Preparation of parents for the ICU experience: what are we missing? Children's health care, 20(3):133-137.

Ranna, W. \& Okay, Y. (1980). Grupos de pais de crianças e da equipe multiprofissional, e sua influência nas diretrizes da enfermaria geral de um hospital infantil. Pediatria, 2:184-190.

Ranna, W. (1987). Aspectos psicossociais da assistência à criança hospitalizada: vivência com grupos de crianças e de pais. Dissertação de Mestrado, Faculdade de Medicina, USP, São Paulo.

Spitz, R.A. (1945). Hospitalism: an inquiry into the genesis of psychiatric condition in early childhood (I).The Psychoanalysis Study of the Child, 1:53-74.

Spitz, R.A. \& Wolf, K.M.(1946). Analitic depression: an inquiry into the genesis of psychiatric condition in early childhood (II). The Psychoan. Study of the Child, 2:313-335.

Apoio CNPqBolsa IC-PIBIC 